\title{
Kaugõppe kujutamine COVID-19 pandeemia esimese laine meemides: huumor kui toimetulekuviis ja enesekaitsestrateegia
}

\author{
Piret Voolaid \\ Eesti Kirjandusmuuseumi folkloristika osakonna vanemteadur \\ Eesti-uuringute Tippkeskuse tegevjuhi ülesannetes \\ piret.voolaid@folklore.ee
}

Teesid: COVID-19 viiruse leviku tõkestamiseks kehtestatud piirangutest üks olulisemaid on olnud tavapärase õppetöö - lähi- ehk kontaktõppe - ümberkorraldamine kodu- ja kaug- ehk distantsõppeks, veebi- ja põimõppeks. Eriolukorraga kaasnenud uus elukorraldus kajastus otsemaid laialdases folklooris, sh internetimeemides.

Artiklis analüüsitakse distantsõppe kujutamist humoorikates meemides, tuues esile nii õpilase, õpetaja kui ka lapsevanema vaatepunkte. Otsitakse vastuseid uurimisküsimustele: millised üleilmsed/kohalikud jooned ilmnevad eesti kaugõppemeemides, kuidas on õpilased kasutanud mitmesuguseid kultuuriressursse (nt popkultuurielemendid, mis on eelnevalt tuntud kirjandusest, filmikunstist, muusikast ja mujalt), mida kõnelevad meemid laste-noorte ja vanemate, samuti õpilaste ja õpetajate suhetest. Üldistades - millised kaugtööga seotud käitumismustrid valitsevad, mida tajutakse koroonaaja distantsõppes probleemidena ja mille üle meemides naljatatakse.

Distantsõppemeemid pakuvad alternatiivse vaate ühele piiranguteajal olulisele õppevormile, aga ka distantsõppega seotud sotsiaalsetele tahkudele ja hariduskriisile laiemalt. Distantsõppega seotud suundumuste kriitilises analüüsis lähtun kvalitatiivsest sisuanalüüsist. Kaugõppepärimuse tõlgendamisel eri vaatepunktidest taaskasutan folkloristikas ja mütoloogiast tuntud ambivalentse tegelase triksteri kuju, kes sobib nii õpilase, õpetaja kui ka lapsevanema rolliga kriisisituatsioonis.

Märksõnad: COVID-19, huumor, distants- ehk kaugõpe, koolipärimus, kriisitoimetulek, meemid, visuaalne kommunikatsioon

\section{Sissejuhatus}

COVID-19 viiruse leviku tõkestamiseks kehtestati 2020. aasta algul kogu maailmas piirangud ja erimeetmed, millest üks olulisemaid oli (õppe)töö ümber-korraldamine koduõppe- ja kaugtöövormi. ${ }^{1}$ Laustaudi esimese laine ajal suleti Eestis koolid alates 16. märtsist 2020 kooliaasta lõpuni. Ka 2020. aasta 
sügistalvel lahvatanud koroonaviiruse leviku teise laine ajal tuli koolid sulgeda ja minna üle kaugõppele. Alates 14. detsembrist olid 25. jaanuarini olid kogu riigis suletud kõik õppeasutused: üldharidus-, kutse- ja kõrgkoolid. Õppetegevus sai jätkuda distantsilt, veebiõppena. Lasteaiad ja -hoiud jäid siiski avatuks. Piirangud kehtisid ka huviharidusele ja -tegevusele, spordile, täienduskoolitustele ja täiendõppele.

Kolmandat korda kehtestati haridusasutustes ranged piirangud kogu Eestis taas 11. märtsist 2021, alates 3. maist lubati kontaktõppele järjest eri kooliastmete õpilased - algul algklassid (1.-4. klass), lõpuklassid (9. ja 12. klass) ja kutseõppeasutuste õpilased, kes sooritasid 2020/2021. õppeaastal riigieksameid. Koolis on võinud viibida õppijad, kes vajavad hariduslikke tugiteenuseid, konsultatsioone või teevad teste. Kutsekoolides toimuv praktiline õpe tuli võimalusel edasi lükata (kriis.ee).

Tervisekriisist kasvas kiiresti välja hariduskriis ning eriolukorraga kaasnenud uus eluviis ehk kaugtöö ja distantsõpe ning nendega seotud iseärasused kajastusid otsemaid ka laialdases folklooris, sh nii Eestis kohalikul kui ka rahvusvaheliselt globaalsel tasandil levinud internetimeemides (vt ka Hiiemäe \& Kalda et al. 2020; Kuperjanov 2020). Iseenesest pole mitmepaikses, liitreaalses, mitmeplatvormses tööviisis midagi uut, kodukontori võimalus oli Eestis väga paljudes asutustes kasutusel juba eriolukorra eelsel ajal. Seda on võimaldanud Eesti elanike hea varustatus interneti ja digitehnoloogiaga. Ka kaugõpe on ammu tuntud pedagoogiline õppetöö vorm, mille teadvustatud tekkeaega seostatakse 19. sajandi lõpu USAga, aga ka juba varasema ajaga.

Koroonapandeemiaga seoses täpsustunud õppevormid ja digiõppeterminid näitavad seda, kuidas õpitakse terve ainekursuse või õppekava vältel. Haridusja Noorteameti ${ }^{2}$ kodulehelt (https://kompass.harno.ee/unelmate-distantsope) leiab lihtkoelise mõistekompassi. Kaug- e distantsõpe (distance learning) on pedagoogikas õppetöö vorm, mille kaudu omandatakse haridus iseseisvalt (nt töö kõrvalt õppides, pigem on see seni olnud kasutusel täiskasvanute puhul). Kui lähi- e otseõpe (face to face learning) toimub terve õppeaja vältel silmast silma ühises füüsilises ruumis, näiteks klassiruumis või auditooriumis, laboris või seminariruumis, siis kaugõppes on vastupidi: õppijad ja õpetajad on kogu kursuse ajal füüsiliselt üksteisest eraldatud.

Laustaudi ajal sai oluliseks kaugõppe alaliigiks veebiõpe (online learning) kui õppevorm, kus õppetöö toimub täielikult veebis ja seda rakendati koroonaaja distantsõppes ohtralt. Lisaks on oluline õppevorm hübriidõpe (hybrid learning), milles kombineeritakse kaug- ja lähiõpet. Hübriidõpe jaguneb omakorda põim- ja paindõppeks. Põimõpe (blended learning) on õppevorm, kus õppetöö toimub osa ajast füüsiliselt klassiruumis ja vahepeal kasutatakse kaugõpet. Paind- e hajaõpe (hybrid flexible learning, HyFlex learning) on õppevorm, 
mille puhul kombineeritakse auditoorset ja kaugõpet nii, et osa õppijaid on füüsiliselt klassiruumis ja teine osa ruumiliselt eraldatud. E- e digiõppena (e-learning) käsitletakse digivahendite kasutamist õppetöös, mis võib toimuda nii lähi-, põim-, paind- kui ka veebiõppes. Koduõpe (homeschooling) on aga õppevorm, kus õpe toimub tavaliselt lapsevanema soovil või lapse tervisest tingitud põhjustel kodus, haiglas või mujal väljaspool kooli. Pandeemia ajal siirdus õppimine kooliruumist koduseinte vahele, sest koolid suleti eriolukorra tõttu.

Samas oli koolikorralduses kaugõpe ja üleminek klassiõppelt põhiliselt veebiõppele nooremate õpilaste jaoks pigem erakordne ja tavatu. Ka kõrgkooliloengud ja -seminarid on meil olnud füüsiliselt auditooriumis, seega tuli just õppetöö ümberkorraldamisega rohkem või vähem vaeva näha. Siin sai oluliseks tehnoloogiavõimaluste ärakasutamine.

Kaugõppel on kindlasti häid külgi, kuid koroonaajal hakati eri kanalite kaudu kiiresti kõnelema selle vormi keerukustest, nt nooremate õpilaste puhul tuli tervel perel kohaneda kodus laste õppimise korraldamisega - pere pidi tagama päevakava ja sellest kinnipidamise, leppima kokku, kes ja millal aitab last, kui ta ei suuda iseseisvalt õppida. Tekkis rohkelt küsimusi. Näiteks kuidas motiveerida last? Kes aitab lapsevanemat, kui tema digipädevus on kehv? Kuidas käituda, kui e-ülesanded jäävad õigeks ajaks tegemata? Ka tehnika olemasolu võis pere elukorralduses probleemiks kujuneda.

Õpetaja seisukohast oli põhiprobleem, kuidas ainet anda edasi veebivormis, nii et see tõesti kõigini jõuaks. Või kuidas kontrollida ja tagada, et kõik kaasa teeksid, kaasa mõtleksid.

Väga kiiresti hakati rääkima ja tegema esmaseid uuringuid distantsõppe mõjust õpilaste vaimsele tervisele. Üks Eesti Noorte Vaimse Tervise Liikumise küsitluse kokkuvõte (ENVTL 2020) on tehtud juba koroonaviiruse leviku esimese laine ajal aprillis 2020 ja selles on välja toodud viis tüüpilisemat probleemi.

1. Pooled vastanutest tajusid enda vaimse tervise seisundi halvenemist eriolukorras.

2. Vaimsete raskuste keskmes on paljude noorte jaoks oma mõtetega üksi jäämine.

3. Distantsõppega kaasnev pikenenud ekraaniaeg ning eriolukorras märkimisväärselt kahanenud võimalused huvitegevuseks - oluline tegur vaimse ja füüsilise tervise halvenemisel.

4. Pere ja lähedastega seotud temaatika on mitmetahuline:

a) osa tajub stressiallikana pereliikmetega lähikontaktis veedetud mitmekordistunud aega ja piiratud võimalusi omaette olemiseks. Sellega kaasneb paljudele kodus lõksus olemise tunne, suurem 
hulk konflikte, piiratud võimalused saada tuge (vaimse tervise spetsialistidelt, sõpradelt) video- või telefonikõnede vahendusel.

b) paljud noored on jäänud üksi ja tunnevad, et neil ei ole kellegagi oma muresid jagada. Soovitakse, et oleks keegi, kellega suhelda; ohus on noored, kes elavad täiesti üksi, kes tunnevad hirmu tõsiste muremõtetega toime tulemise üle.

5. Suur stressiallikas on distantsõppele järsu üleminekuga kaasnenud õppekoormuse tõus ja e-õppes antavate ülesannete ja juhiste killustatus eri platvormide vahel. Raskuste allikas on ka sobiva õpikeskkonna puudumine ehk koduste tingimuste mõju õppimisele. (ENVTL 2020)

Sellise uuringu valguses tekib küsimus, kas ja kuidas kajastuvad nimetatud probleemid distantsõpet kujutavas rahvahuumoris, mis väljendus iseäranis rohkelt internetimeemides. Eesti juhtumi näitel toon esile meemides ilmnevad erinevad vaatepunktid: õpilase, õpetaja, lapsevanema positsioonid. Ühtlasi vaatlen, millised globaalsed-lokaalsed jooned ilmnevad meemides. Kuidas on õpilased kasutanud neis meemides muid kultuuriressursse, nt popkultuurist, sh varasemalt kirjandusest, filmikunstist, muusikast jt olulistest kultuurinähtustest tuntud motiive ja elemente? Kas ja kuidas väljenduvad nt (laste-noorte ja vanemate vahelised) peresuhted, (õpilaste ja õpetajate vahelised) koolisuhted, millised kaugtööga seotud käitumismustrid valitsevad jne?.

\section{Teoreetilised lähtekohad}

On üldteada tõde, et igasuguste segaduste ja uute olukordadega kohanemisel on ikka olnud abi huumorist. Näiteks psühhoanalüütiliste ehk lõõgastusteooriate (Deckers \& Buttram 1990; Jürgens \& Fiadotava et al. ilmumas) järgi on huumor psühholoogiline ventiil pingete väljalaskmiseks. Lisaks tulevad arvesse ka kognitiiv-tajumuslikud ehk inkongruentsusteooriad, mis aitavad välja selgitada tehnilisi vastuolusid ja üllatusmomente, mis nalja esile kutsuvad (Attardo 2014). Folkloristlikust tõlgendusviisist lähtudes saab kaugõppega seotud meeme vaadelda folkloori pragmaatika aspektist - loomingulised meemid on suurepärane näide pärimuse praktilistest väljunditest toimetuleku hõlbustajana, neid võib mõtestada kui omamoodi kaitsemehhanismi avaldumist (pärimuse pragmaatikast vt Hiiemäe 2016: 10).

Artikli teoreetilise lähtealuse moodustavad tänapäeva meemiteooriad, milles tähistatakse meemi mõistega interenetiajastul teatud tüüpi interneti-huumorit. Folkloristi jaoks on internetimeem digitaalselt, enamasti pildi ja sõna koostoimes loodud ning digitaalse jagamise teel leviv folkloori lühivorm, mis väljendab 
ja võimaldab uurida ühiskonnas levinud hoiakuid, stereotüüpe ja uskumusiarusaamu. Niisiis teenivad selline huumor ja meemiloome kriisiajal peale pelgalt meelelahutuslike eesmärkide hoopis olulisemat, resümeerides huumoriuurijat Dineh Davist: see lähendab ja ühendab inimesi rasketel aegadel, vähendab olukorra ebakindlust, võimaldab enese- ja rühmakuuluvuse määramist, suurendab sõnumi saatja usaldusväärsust ja annab edasi emotsioone (Davis 2008: $554)$.

Iisraeli huumoriuurija Limor Shifmani (2014: 41) sõnastatud põhjaliku definitsiooni järgi on meemid digitaalsed sisuüksused, millel on ühiseid tunnuseid sisus, vormis ja hoiakus, nende kasutajad on teadlikud teiste sarnaste üksuste olemasolust ning neid levitavad, imiteerivad ja muudavad paljud internetikasutajad. Meemide oluline tunnus on intertekstuaalsus, mis jääb meediumi, inimeste ja sõnumi ristteele (vt Laineste \& Voolaid 2016: 28), st meemid viitavad üksteisele, aga ka ekspluateerivad varasemaid kultuuritekste. Varasemas kontekstis esinenud pilt, lause või mõte tõstetakse uude ümbrusse, vana kas laenatakse iseendana või tehakse sellele üksnes peen vihje. Meeme saavad internetis paljud kasutajad jagada, jäljendada ja/või muuta, nende levikut kiirendavad omakorda sotsiaalmeediaplatvormid.

Populaarne, hästi leviv internetimeem on pigem humoorikas ja positiivne tänapäeva anekdoot, mis kutsub esile tugevaid tundeid. Meemide tegemisel järgitakse alusmalle, mida pakuvad interneti meemigeneraatorid. Huumor on olemuselt sotsiaalne nähtus (vt Kuipers 2009), oluline on interaktiivsus, igaüks saab meemiloomes osaleda ja neid jagada. Meemid võivad väljendada ka ühiskonnakriitikat, neid võib kasutada kogukonnatunde loomiseks või poliitiliseks protestiks. Käesoleval juhul räägitakse meemide kaudu ehk meemikeeles distantsõppega seotud erisugustest tahkudest, millega uues olukorras silmitsi seisid ja seisavad siiani nii õpilased, õpetajad kui ka pered.

Artikli alusmaterjal pärineb põhiliselt kooliõpilastelt ja on seega tänapäeva koolipärimus. Eesti kontekstis on selle teema juures abiks varasem, 2019. aastal ajakirjas Mäetagused ilmunud Mare Kalda ja Astrid Tuisu artikkel koolielu kajastamisest õpilaste omaloodud meemilehtedel kolmes Tartu piirkonna koolis (Kalda \& Tuisk 2019). Distantsõpet kajastavad meemid liigituvad niisiis koolimeemideks, kuivõrd tõlgendavad ja peegeldavad koolielu. Mare Kalda ja Astrid Tuisk (2019: 154) kõnelevad ka meemidest kui teatud subkultuuri tööriistast, noortekultuurile omasest nähtusest, millele on omane vastukultuuriline iseloom. Meemide kaudu võib toimuda kellegi ninapidivedamine, ületrumpamine, väljavihastamine, narritamine, tabuteemadest rääkimine, kuid meemidele on võimalus samaga vastata ning olla nupukas ja taiplik, nende loomise kaudu on võimalik ka ennast arendada. Üht selle kirjutise jaoks küsitletud allikat tsiteerides: 
Meemikeel on täiega minu keel. Tegelikult iga noore keel, me saadame neid kogu aeg üksteisele. Mingi olukord võib olla täielik meem, mõni inimene võib olla täielik meem - see tähendab, et on naljakas. Inimesed ise ei teagi, kuidas võivad meemiks saada, seriaalide tegelased võivad saada meemiks, aga kõigest võib meemi teha - näiteks väikelaste naljakad emotsiooninäod. (Suuline intervjuu, 19aastane tüdruk, mai 2021; EFITA, F33-014-0001)

Niisiis on meemikeel noorte endi sõnul tänapäeva kirjalikus sotsiaalmeedia kõnekeeles sama oluline väljendusvahend kui erinevaid emotsioone väljendavad ikoonid ehk emotikonid, olukordi ja inimesi meemistatakse ja visuaalsete meemide keeles räägitakse omavahelistes veebivestlustes.

Kui spetsiaalsete meemivõistluste ja sotsiaalmeedia postitustena loodud materjali on folkloristil võimalik suhteliselt lihtsalt koguda, siis noorte omavahelistes vestlustes kasutatud meemiaines jääbki privaatseks ega ole kergesti dokumenteeritav.

COVID-19 viiruse tõkestamisega seotud kaugõppepärimuse kirjeldamiseks ja mõtestamiseks sobib folkloristikas ja mütoloogias varem kasutatud tüpaaž trikster (mõiste päritolu kohta vt Brinton 1868). Trikster kui suulise pärimuse universaalsemaid müütilisi tegelaskujusid, kes teeb tempe, kavaldab, rikub häid kombeid, petab ja saab ise petta, leiutab uusi asju ja osaleb kultuuri või kogu maailma loomisel, "kujundab ja muudab maailma, teeb vägitegusid ja kasutab kavalust, kuid võib tihti käituda ka rumalalt või õelalt" (Krull 2006: 31). Huumoriga seoses on triksteri kuju käsitlenud Arvo Krikmann (2002). Hasso Krulli väitel on triksterimuster väga ambivalentne, ta on teispool head ja kurja, ta astub üle igasuguste piiride ja käitub meelega valesti, ta on korraga tark ja rumal (Krull 2006: 30-31).

Varasemas koolihuumoris võime triksterina tõlgendada nt stereotüüpset anekdooditegelast, ninakat koolipoissi Jukut, koroonaolukorras tuli uues olukorras kõigil rohkem või vähem ümberkorraldusi teha ja tihti ka triksterliku nutikusega probleeme lahendada. Küsimus on, kuidas see käesolevas meemimaterjalis väljendub.

\section{Allikad ja analüüs}

Artikli allikabaasi moodustab EKM folkloristika osakonna teadusarhiivi EFITA meemikogu, millesse lisandus koroonaajal üle 2000 erisisulise meemiüksuse, samuti Eesti Rahvaluule Arhiivi koroonapärimuse kogumise käigus laekunud meemid. 
Eraldi uurimisaines on konkreetse kontekstiga seotud, teatud aktsiooni tulemusena loodud materjal. Nimelt kutsus Tartu Variku Kool aprillis 2020 Tartu koolide õpilasi üles jagama oma distantsõppe kogemust ülelinnalisel meemikonkursil "Minu distantsõpe", millele saadeti kokku 541 teemakohast meemi. Laekunud ainese andis võistluse peakorraldaja Tartu Variku Kooli huvijuht Eele Avalo mais 2020 üle eesti huumoriuurijatele ja see jääb tallele Eesti Kirjandusmuuseumi teadusarhiivi. Lisaks vaatasin ka Eesti Rahvaluule Arhiivi koroonapärimuse kogu, milles leidus samuti mõningaid kaugõpet kujutavaid meeme. Võistluse kaudu kogutud materjal on võrreldav teatud temaatiliste avatud vastustega küsitluskavadega kogutava ainesega. Folkloristikas on sellisel viisil allikate loomine tavapärane, etteantud teemadele tuginevad varasemad üle-eestilised koolipärimuse kogumisvõistlused, eluloovõistluste üleskutsed). Nii nagu folkloristikas on allikaloomise mõistetena juurdunud teemakirjutus ja teemajutustus (Apo 1995; Jaago 2018: 5), nii saame käesoleval juhul kõneleda etteantud teemal loodud meemimaterjalist ehk teemameemidest.

Kuulun pandeemia esimese laine algusest peale rahvusvahelise koroonafolkloori ja -huumori uurimise projekti "Humor during the global Corona Crisis", seetõttu moodustab rahvusvahelise tausta ka see materjal - umbes 12000 nalja. Koostööprojekti juhtpartnerid on Giselinde Kuipers (Leuveni Katoliiklik Ülikool) ja Mark Boukes (Amsterdami Ülikool) ning projekti on kaasatud rohkem kui 30 riigi teadlased. Eri keeltesse tõlgitud küsitluskava (https://edu.nl/ kp8xe) kaudu paluti inimestel saata internetikasutajate hulgas levivaid nalju, sh meeme. Globaalne kogu on 2021. aasta algusest peale võrdlevate uuringute eesmärgil kättesaadav kõigile projekti osapooltele).

Globaalsus esildub nähtavalt meemimallides. Interenetis on lai valik meemigeneraatoreid ja -keskkondi, mille abil on kõigil võimalik meeme kerge vaevaga luua, kopeerida, muuta ja jagada. Omalt poolt tehakse meemialustele tekstilisi või visuaalseid lisandusi. Ka käesoleva artikli allikkorpuses ilmneb meemilehtedelt võetud meemimalle.

Mallid on tuntud popkultuurielementidega, popkultuuritegelastega ja pärinevad noorte hulgas teatud ja tuntud multifilmidest, seriaalidest, koomiksitest, filmidest, trendivälgatustest, mis on puhanguna levinud. Nt eesti materjali hulgas vaieldamatuks populaarsemaks malliks oli konkursimeemides Kanada räppar Drake'iga alus (joonised 1-3, 37), kuhu on võimalik kirjutada ebameeldiv ja meeldiv tunne, tegevus, olukord vmt. Väga levinud mallid on ka "Running Away Balloon" (“Äralendav õhupall”, joonised 4-5) ja "Distracted Boyfriend” ("Hajameelne või segaduses poiss-sõber").

Rohkelt on ekspluateeritud tuntud Ameerika joonissarjade motiividega aluseid, nt Käsna-Kalle Kantpüks, Simpsonid, Spiderman, erinevad muusikud ja näitlejad, videomängude tegelased. Selliste intertekstuaalsete viidete 
väljatoomine annab infot nii globaalsete trendide kui ka lokaalsete traditsioonide kirjeldamisel. Ja peab tunnistama, et visuaalsetes lahendustes vihjeid kohalikele eesti kultuuritekstidele napib. Suurt meemide hulka arvestades on neid vähe, nt "Buratino tegutseb jälle" telelavastuse pilt (joonis 6) ning meem, millelt tunneme ära eesti õppematerjalid (joonis 7).
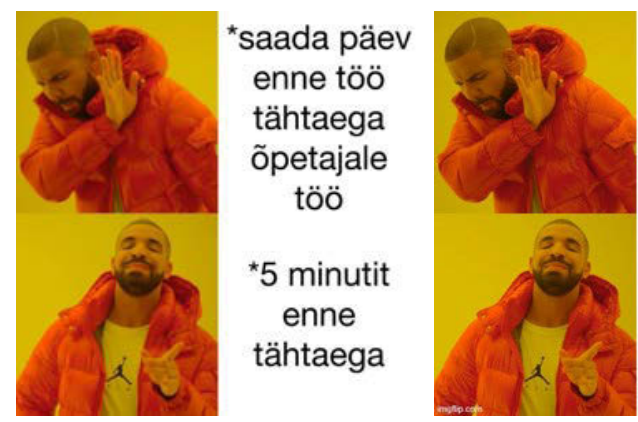

\section{Õpilased videotunnis}

\section{Kodutöö}

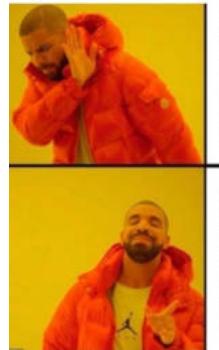

kaamera

lahti,

suhtlevad

opetajaga ja

teiste

õpilastega

Arvutis mängimine

kaamera

kinni, mikker

maas ja

videomängud lahti

Joonised 1-3. Kanada räppar Drake’iga meemialus "Drake Hotline Bling” on eesti materjali hulgas üks korduvamaid globaalseid meemimalle.
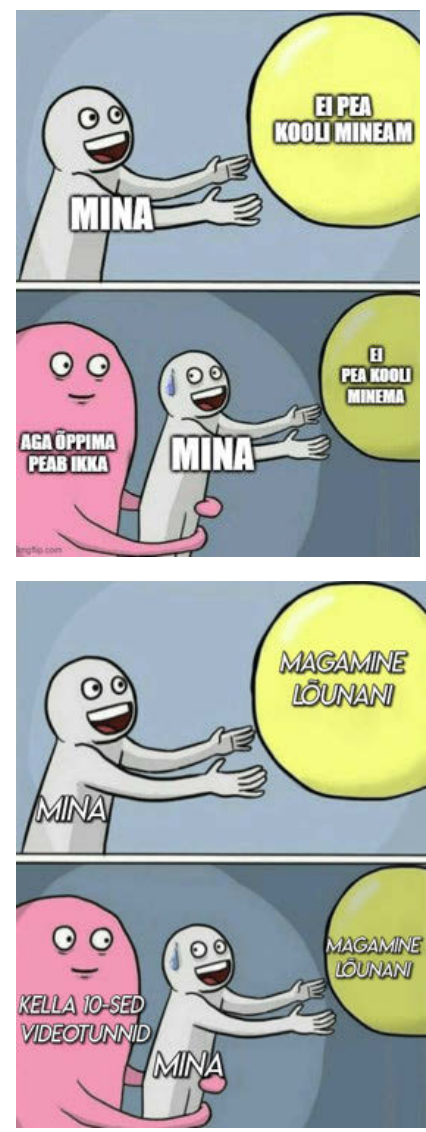

Joonised 4-5. Levinud meemialusele "Running Away Balloon" loodud meemid.
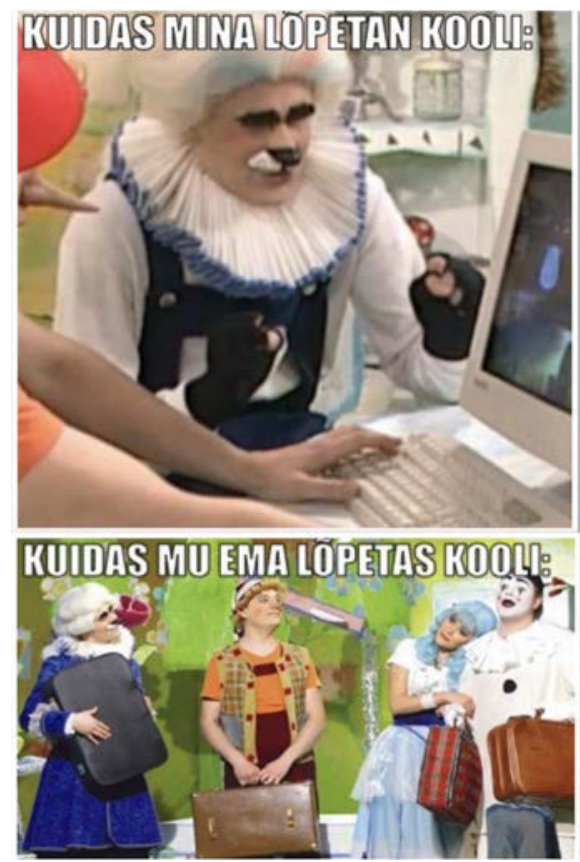

Joonis 6. Telelavastusest "Buratino tegutseb jälle” tuntud tegelastega meem. 
Joonis 7. Eesti õppematerjali alusel koostatud meem.

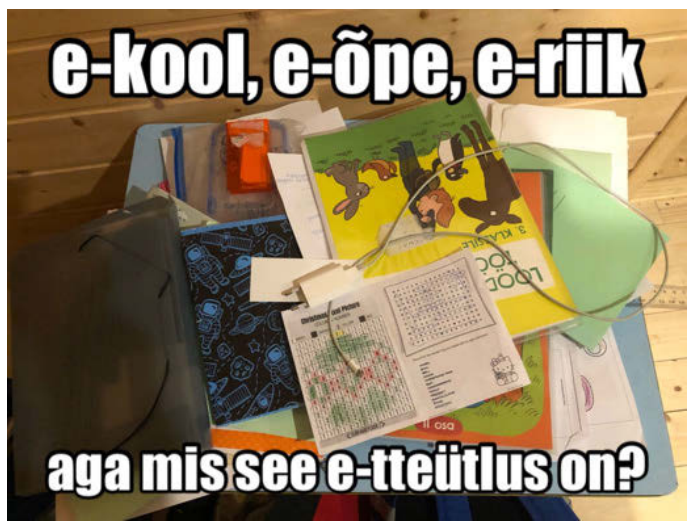

Nii nagu on eri riikides kehtestatud distantsõppekorraldusel palju globaalselt universaalset, nii on distantsõpet kujutavates meemides palju sarnast, nad on hõlpsasti tõlgitavad ja ületavad riigipiire (vt nt Eestis ja Belgias levinud meemid, joonised 8-9). Vene folklorist Tatjana Bauer (2021: 668) on kaugõppemeeme nimetanud omalaadseks karnevaliseerimiseks - meemistamine õõnestab valitsevat korda ja vabastab sellega seotud pingelise atmosfääri huumori ja kaose kaudu.

Populaarsemate mallide näiteid, mida konkursitöödes on kasutatud, on tõesti väga palju. Mõni meemitegija on saatnud ka mitu meemi, nt Tartu Kutsehariduskeskusest on üks õpilane lausa 23 meemi autor. Väga stiilsed ja omanäolised on Karlova kooli 9. klassi tüdruku seitse meemi, millest üks (joonis 11) kuulub ka esiviisikusse.

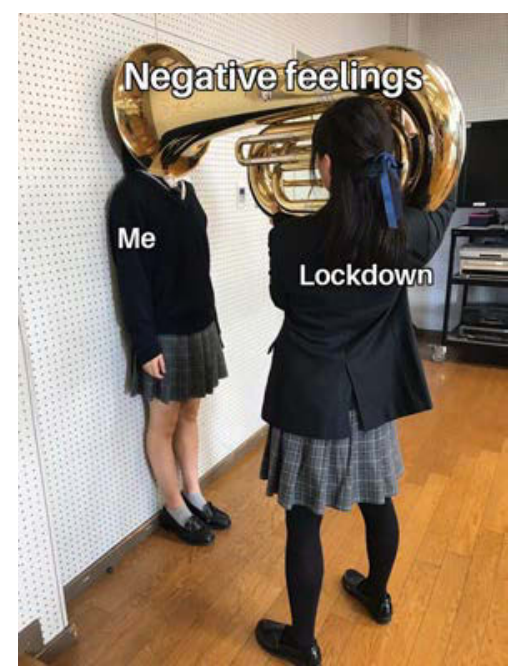

Joonis 8. Belgiast kogutud meem. Belgium_R_Z983ohOBTtaqaIN Girl_ Putting_Tuba_On_Girls_Head.

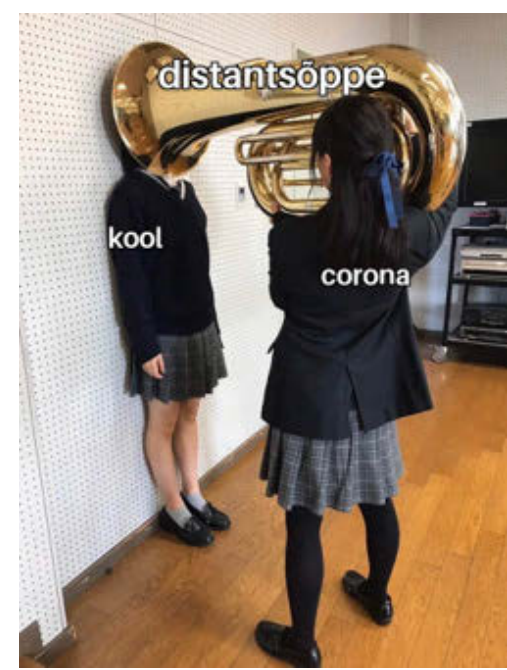

Joonis 9. Eestist kogutud meem. 


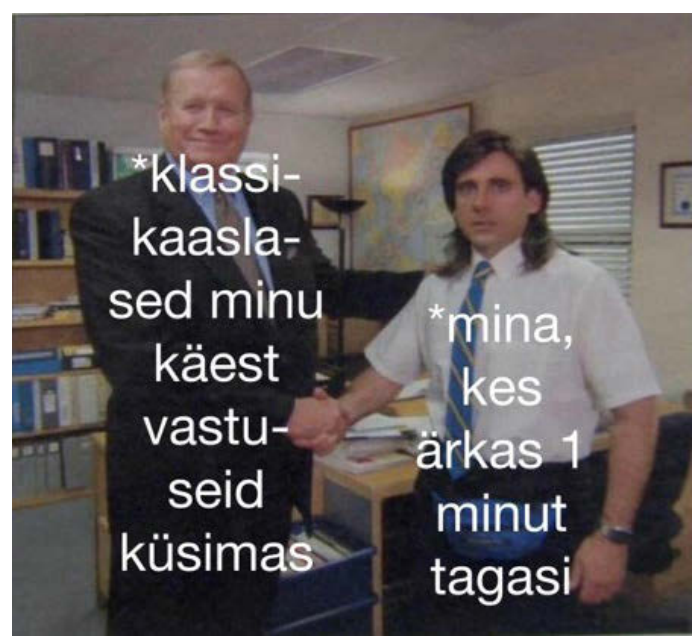

Joonis 10. Meemivõistluse "Minu distantsõpe" võidumeem.
Tegelik põhjus, miks paljude õpilaste õpitulemused paranenud on:

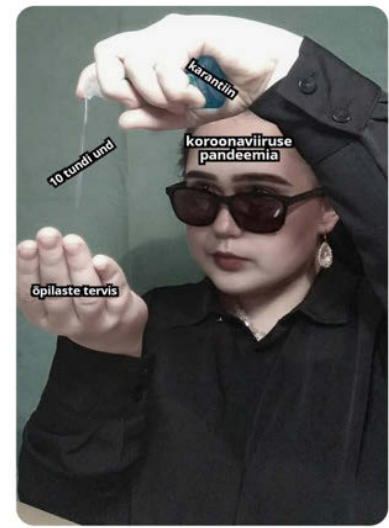

Joonis 11. Võistluse II koht.

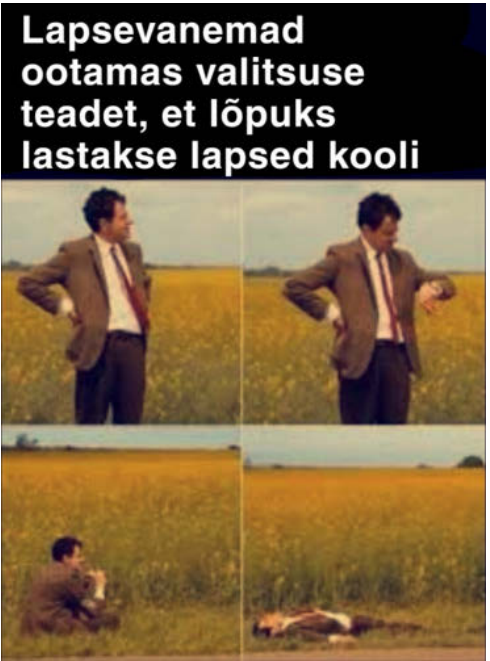

Joonis 12. III koht.

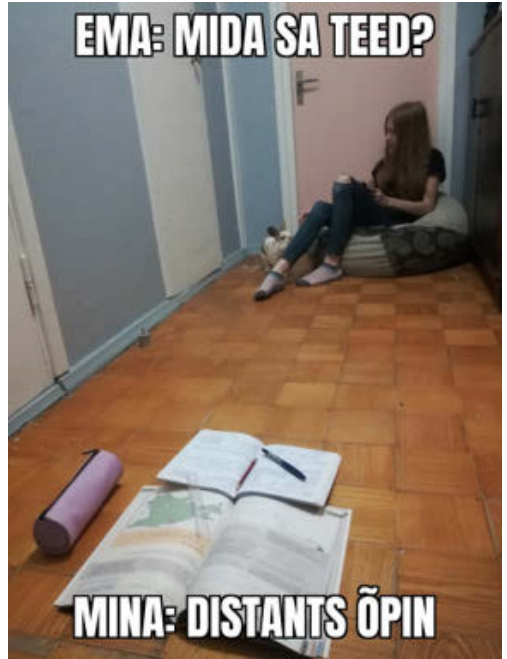

Joonis 13. IV-V koht.

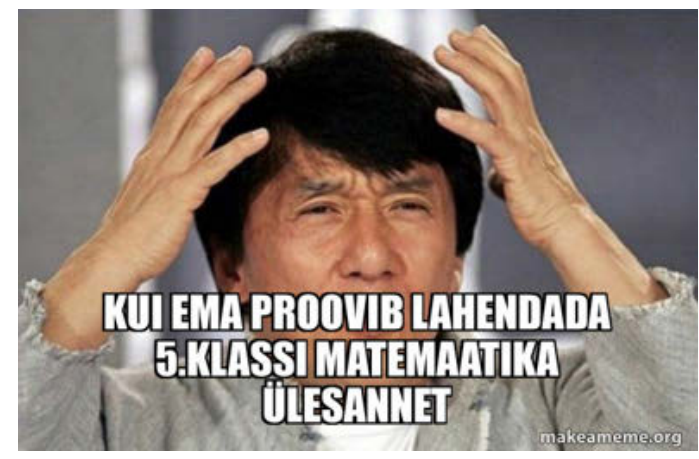

Joonis 14. IV-V koht. 
Silma paistavad universaalsed visuaalsed motiivid, nt kassipildid, ilmekate lapsenägude pildid, mis pole koroonaajale spetsiifilised, vaid esindatud rohkelt muudelgi aegadel ja muudegi teemade korral.

Materjali tõlgendamiseks ja uurimisküsimustele vastamiseks sobib kvalitatiivne sisuanalüüs (vt Laherand 2008; Lagerspetz 2017), mille kesksed ühikud on internetimeemid. Distantsõppega seotud suundumuste kriitilises analüüsis on oluline kompleksne lähenemine meemidele ja nende kontekstiline tõlgendamine. Pildi ja tekstiosa koostoimes tekkiv sõnum, mis avab ka erinevad vaatepunktid, on omakorda asetatud ajastuomasesse koroonapandeemia aega. Materjali kirjeldavas struktuuris lähtun kolmest üldisemast kategooriast, milles on vastavalt esiplaanil kas 1) õpilase, 2) lapsevanema või 3) õpetaja vaatenurk. Kvalitatiivse sisuanalüüsi meetod võimaldab kaugõppemeeme uurida just neis sisalduvatest erinevatest vaatenurkadest.

\section{1. Õpilase vaatenurk meemides - õpilane kui olukorra ülekavaldaja või trikster}

Konkursi teema "Minu distantsõpe" oli püstitatud minakeskse vaatenurgana, nii on loomulikult valdav osa ainest mina-positsioonilt. Samas on õpilase suhtevõrgustikus esindatud kaasõpilased, õpetaja, lapsevanemad, kodus ka nt koduloomad. Variku kooli võistluse esikoha pälvinud meem (joonis 10) kannabki just sellist ideed: "Klassikaaslased minu käest vastuseid küsimas. Mina, kes ärkas 1 minut tagasi."

Paljud meemid kujutavad dilemmat kohustuse ja õpilasele meeldiva vahel, mida siis kohustuse asemel salaja tehakse. Põhimõtteliselt ei ole selline kohustuste/meeldiva vahekord võõras ka lähiõppes, kuid kaugõppe visuaalsetes meemides on see teema eriti ilmne ja uue elukorralduse juures on õpetaja petmine iseäranis lihtne. Meeldivatest tegevustest kohtame rohkelt magamise ja une motiivi. Sel ajal kui distantstund juba käib, on koduõppe tingimustes võimalik videokaamera välja lülitada, nii et õpetajale jääb mulje tunnis osalevast õpilasest, ja ise samal ajal hoopis magada.

Kui paned endast gifi/pildi live tundi ja lähed ise magama

Joonis 15. Triksterlik tegelane Megamind sobib tegelaseks, kellega end samastada ja õpetaja videotunnis üle kavaldada.

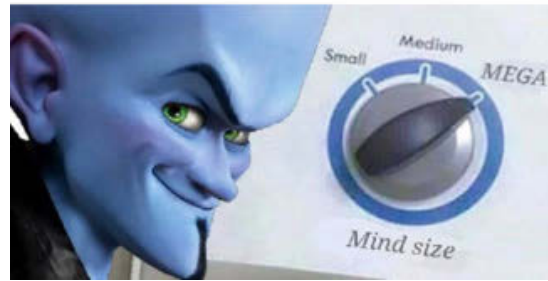


Õpilane on tõeliselt triksterlik kavalpea, tüssaja, olukorra enda kasuks kavaldaja. Selline vigurvänt on näiteks sinise nahaga humanoidne tulnukas Megamind (joonis 15), popkultuurist, videomängust ja populaarsest joonissarjast pärit supergeeniusest kangelane. Kaksikelu ja triksterlikku näivust kajastavas meemis kohtuvad õpilase tegelikud soovid ja kohustuslik avalik pale.

Ilmnevad teatud tendentsid või mustrid, mille järgi saab meeme liigitada. Meemide põhjal saab õpilane justkui selle olukorraga hakkama, aga samas on ta sundseisus ja piiratud valikute puntras, mis algab juba kriisiajale omasest selgete sõnumite puudusest, sageli vallanud teadmatusest isegi selle kohta, kas koolitöö toimub lähiõppena või suunatakse digiõppele. Meemides kajastuvad elulised äpardused. Täiskasvanugi teab nördimustunnet, mis valdab, kui tehtud töö tuleb ümber teha või kui tehnika altvedamise tõttu ei pääse tunni keskkonda. Ka kontaktõppel võib pingeid tekitada hetk, mil õpetaja valib nimekirjast õpilase nime, keda vastama kutsuda. Paljud mäletavad kooliajast kontrolltööga seotud emotsioone. Aga meemides kajastuvad ka naljakad äpardused, kui mõni õpilane on kõvasti välimusega enne videotundi vaeva näinud ja ühtäkki selgub, et tunni aeg on segi läinud ja ettevalmistusteks kulunud vaev on olnud asjata.

Eesti kooliõpilaste meemides kohtab ka makaroonilist keelekasutust (nt joonised 16-17, 24, 41), segakeelsust mõjutab oluliselt inglise keel.

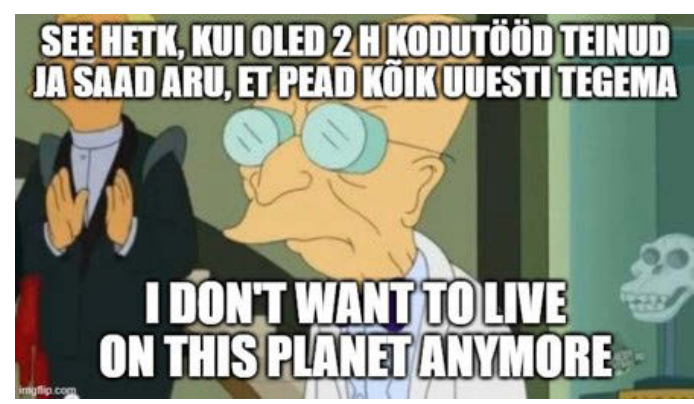

Joonis 16.

Köik klassikaaslased videokõnes Mina, kes jäi videokõnesse tuliselt millegi üle arutamas: 10 minutit hiljaks:

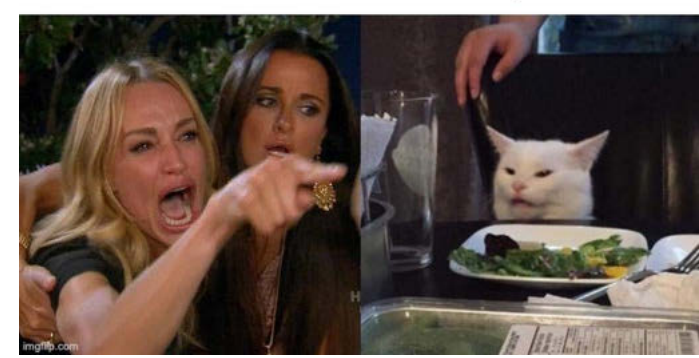

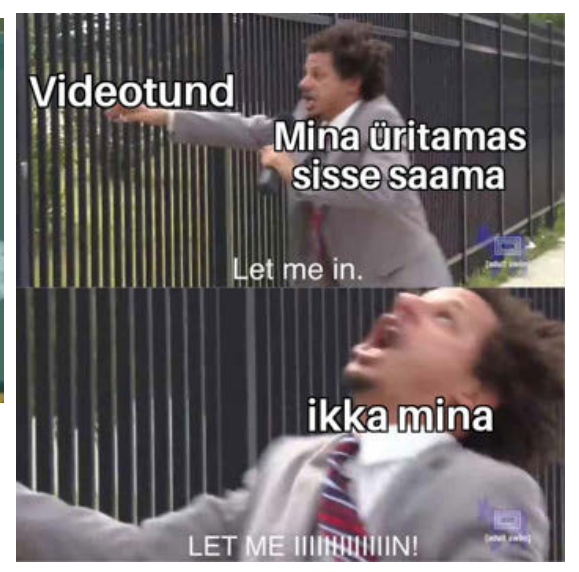

Joonis 17.

Joonis 18. 

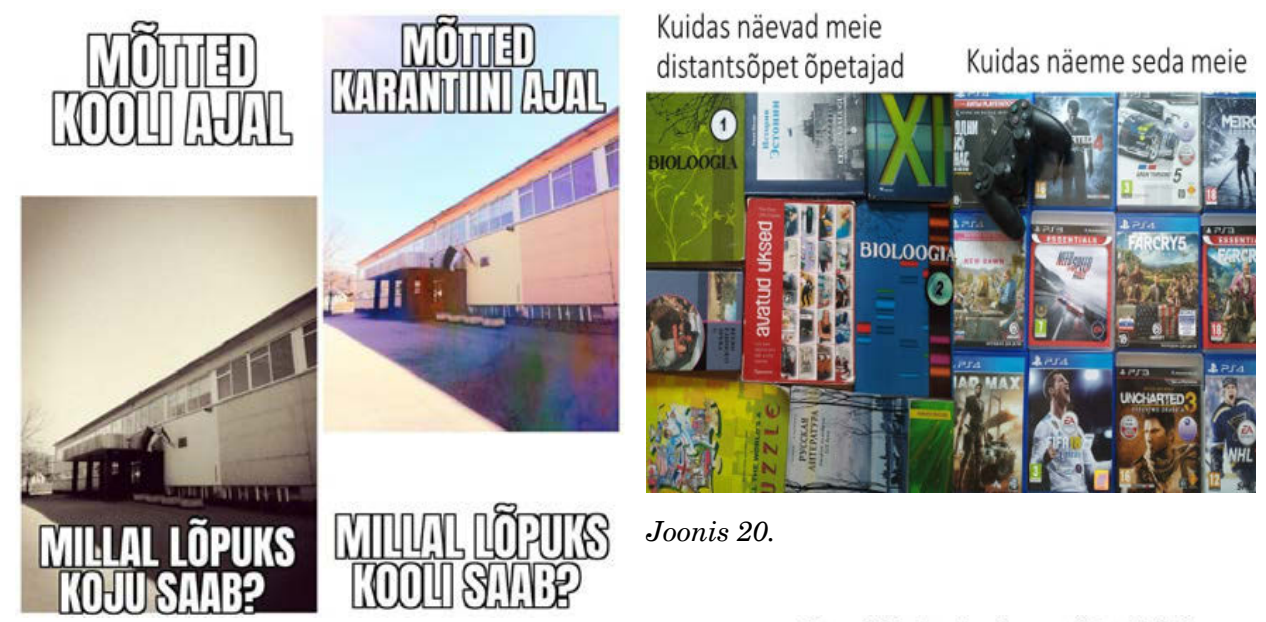

Joonis 20.

Joonis 19.

Tunni üle laskmine, märts 2019

Sageli on meemid üles ehitatud vastandusele mina vs. teised (nt õpetaja, lapsevanemad, koolikaaslased, nt joonised 10, 18, 19). Koroonaaja distantsõpet võrreldakse koroonaeelse, $\mathrm{nn}$ normaalse ajaga, 2019. aastat 2020. aastaga (joonised 20-21).

Tavaarusaama kohaselt õpilased pigem ei taha koolis käia, kuid suur osa meeme väljendab soovi koolis käia ja igatsust endise elukorralduse järele. Väga inimlikuna kõlab iha teha seda, mille tegemine on parajasti võimatu. Meemid kirjeldavad olukorda, kus saadakse küll kodus õppimisega hakkama, aga igatsus jääb kvaliteedi järele, mida saab pakkuda ainult füüsiline koolisolemine (joonised 22-23).
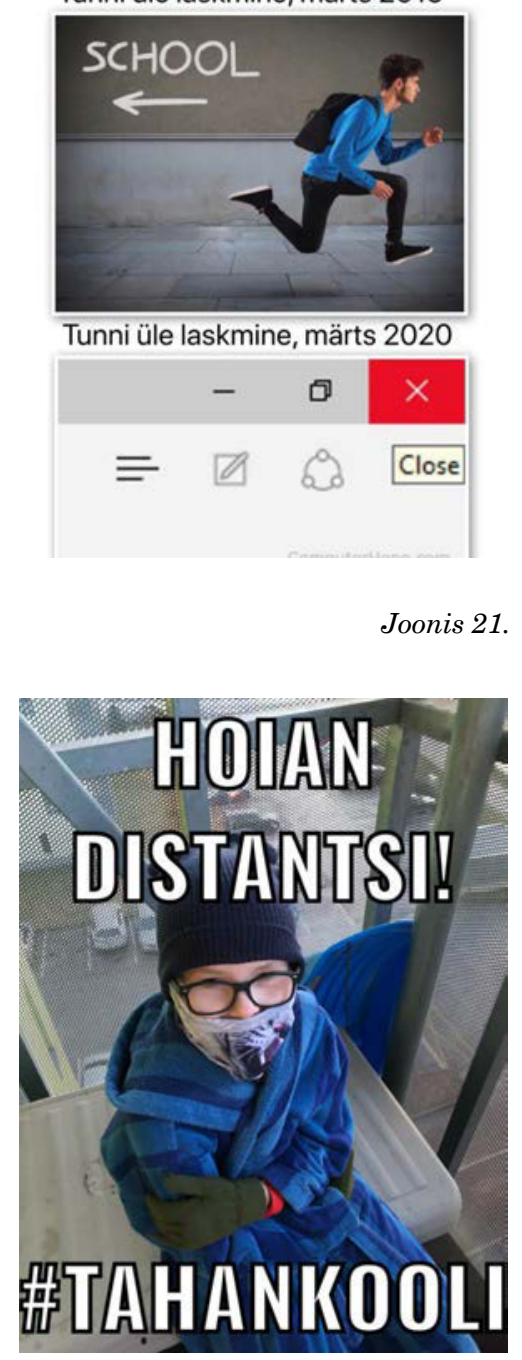

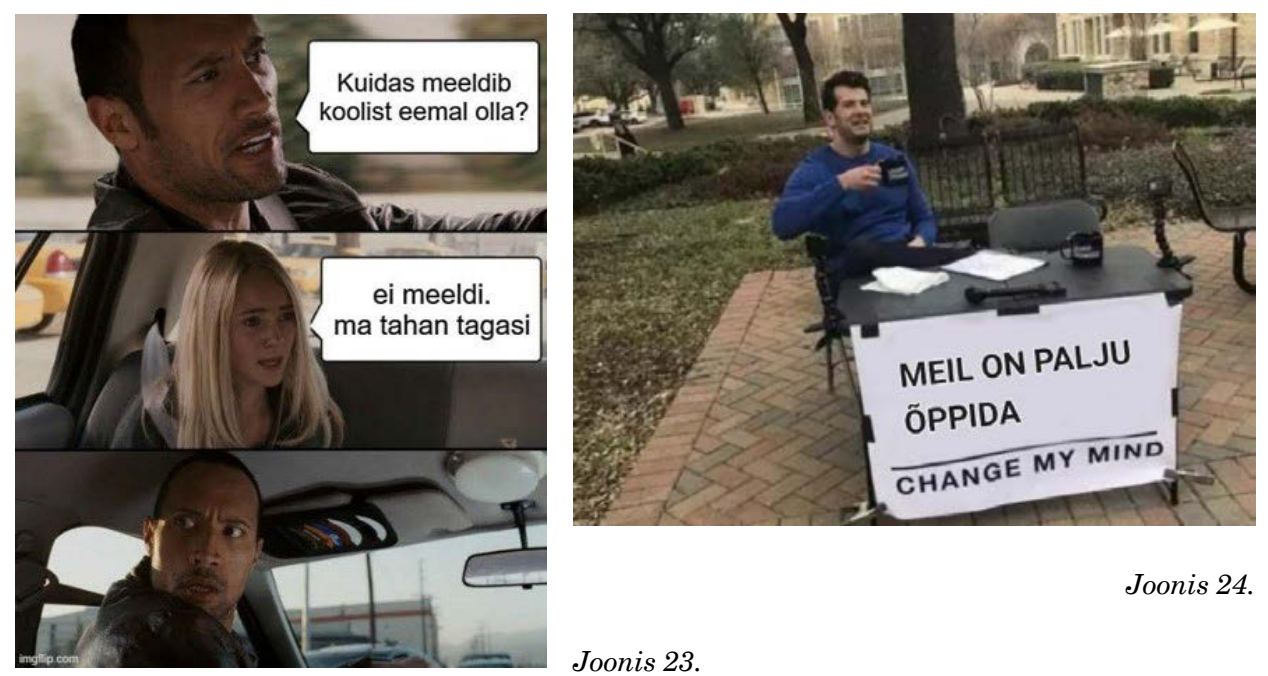

Joonis 24.

Joonis 23.

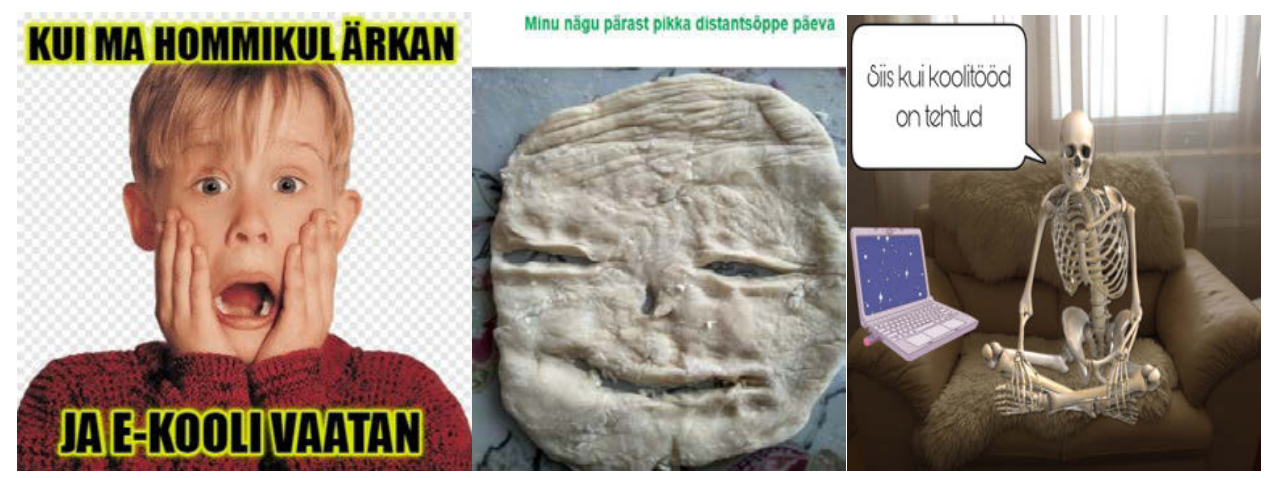

Joonis 25.

Joonis 26 .

Joonis 27.

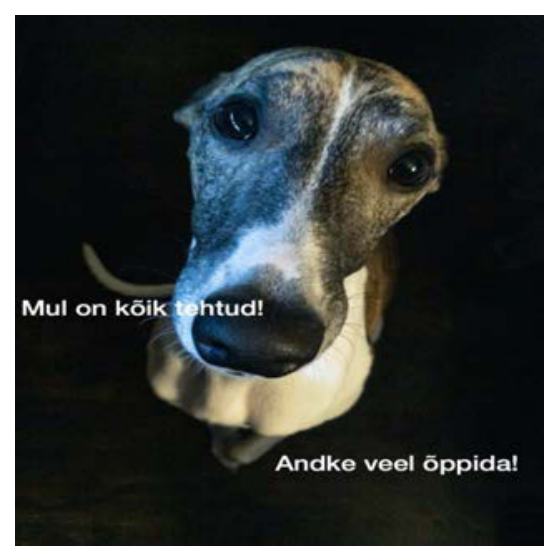

Joonis 28.

Joonis 29.

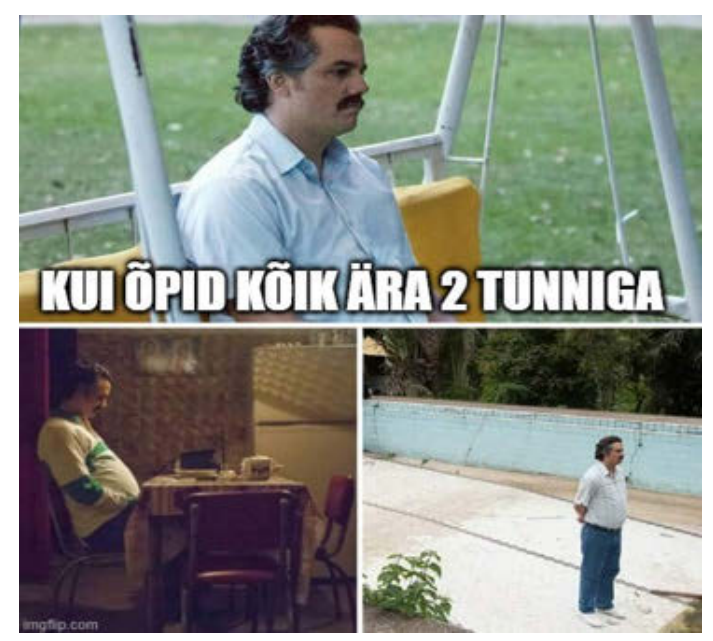


Paljudes meemides kurdetakse vastupidi, et õppida on liiga palju (joonised 24-25). See langeb kokku ka sissejuhatuses toodud distantsõppe probleemide küsitlusega - iseseisva töö osakaaluga ei pruugi kõik edukalt hakkama saada. Samas võib koduste ülesannete rohkus ka tavaolukorras paljudele õpilastele muret teha. Meemides väljendatakse allaandmist, mis juhtub pärast pikka distantsõppepäeva, kui lõpuks on koolitööd tehtud, kokkuvarisemisega kaasnevat emotsiooni väljendavad visuaalis kujundlikult nt tainanägu (joonis 26) või luukere (joonis 27).

Meemides leidub ka vastupidine sõnum: õppida antakse liiga vähe ja distantsõppe kahjuks räägibki hoopis see, et kodus on igav, ei saa kaasõpilastega suhelda, tuntakse puudust seltskonnast ja koosolemisest (joonised 28-29). Distantsõppega võivad kaasneda hoopis paremad õpitulemused, seda soodustavad kodused olud, ka tundub, et karantiini ajal saavad õpilased kauem magada, mistõttu on nad vähem väsinud.

Nii mõneski meemis avalduvad konkreetsemad probleemid, distantsõppe suureks komistuskiviks võib osutuda nt õppetööks vajaliku arvuti puudumine (joonis 30). Või ollakse üksi oma öiste muremõtetega, hakkamasaamise hirmudega (joonis 31). Esindatud on muidki õppetööd segavaid koduseid tegureid nt allumatu väike vend või õde, kes võib lihtsalt keskendumist takistada, aga ka korraldada mõne pahanduse, nt töövahendeid rikkuda (joonis 32).

Mitmed meemid kuulutavad sõnumit, et kaugõpe on ka meeldiv. Meeldivale poolele saab kanda õpetajate äärmiselt loomingulise lähenemise distantsõppe ajal. Mänguliselt mõjub ühe Tartu kooli kehalise kasvatuse õpetaja antud ülesanne liikuda sellist trajektoori mööda, et joonistub vastav kujutis (joonis 33).

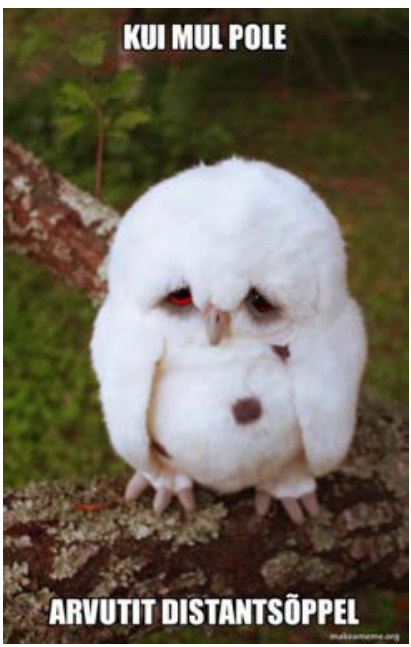

Joonis 30 .

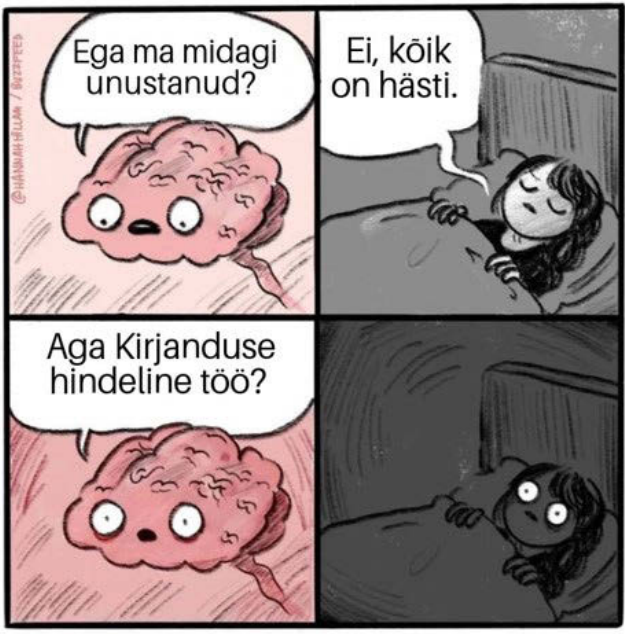

Joonis 31 . 


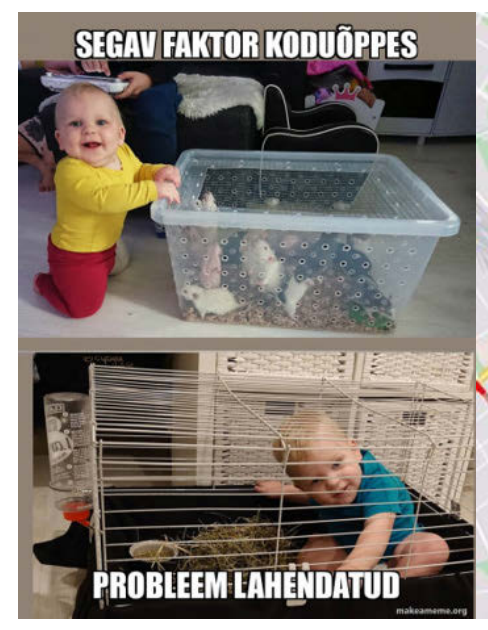

Joonis 32.
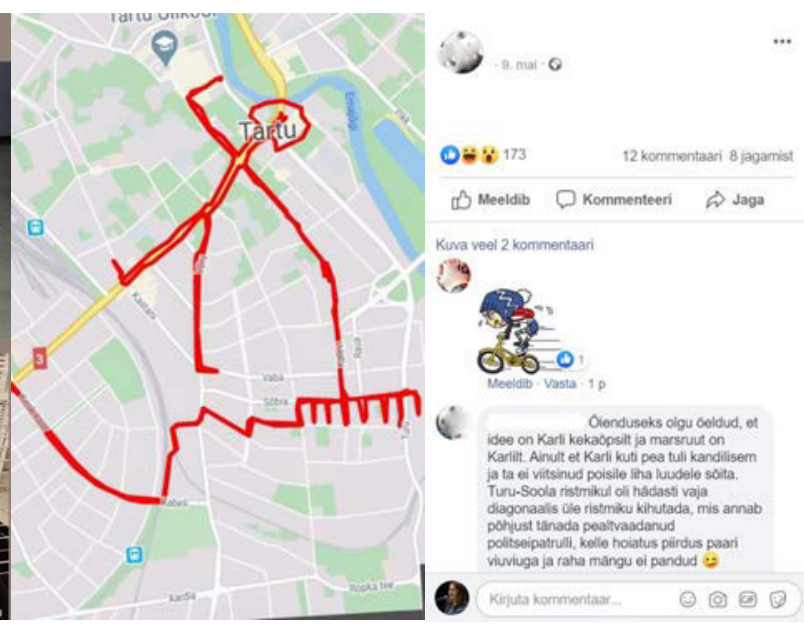

Kuwa veel 2 kormmentaari

19

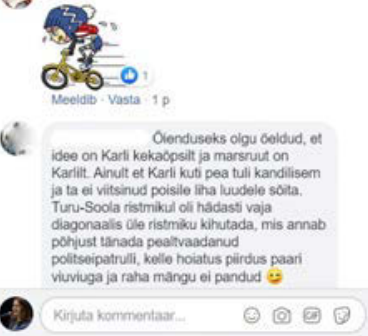

Joonis 33 .

\subsection{Lapsevanemate roll distantsõppeteemalistes meemides}

Õpilase suhtevõrgustikus on distantsõppe korral olulisel kohal lapsevanemad, kes viibivad samuti eriolukorras põhiliselt kodus ja kellel lasub tihti isikliku kaugtöö ja koduse elu ja olme eest vastutamise topeltkoormus. Võistluse "Minu distantsõpe" meemides avaneb lapsevanema vaatepunkt läbi õpilase silmade. Olenevalt õpilase east kaasneb koduõppega tahes-tahtmata ka lapsevanemale suurem roll lapse tegemiste kontrollijana, n-ö õpetaja koduse asemikuna. Koosôppimist pole meemides võimalik tuvastada, pigem esinevad lapsevanemad autoritaarsel positsioonil ja järelevalve korraldajana (joonised 34-35).

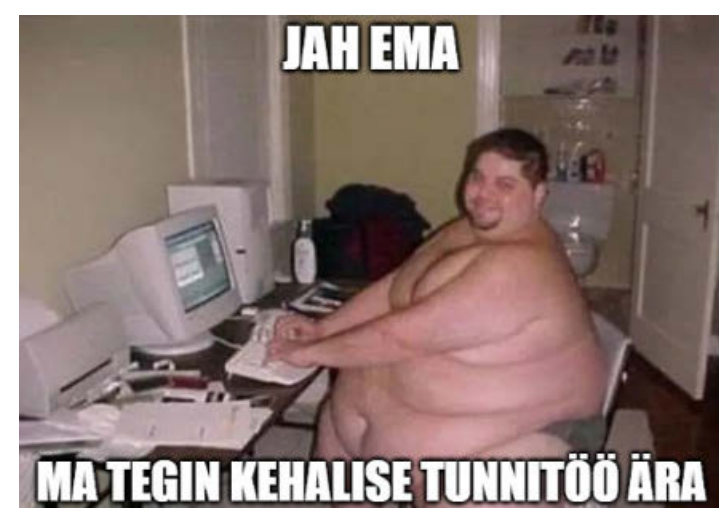

Joonis 34 

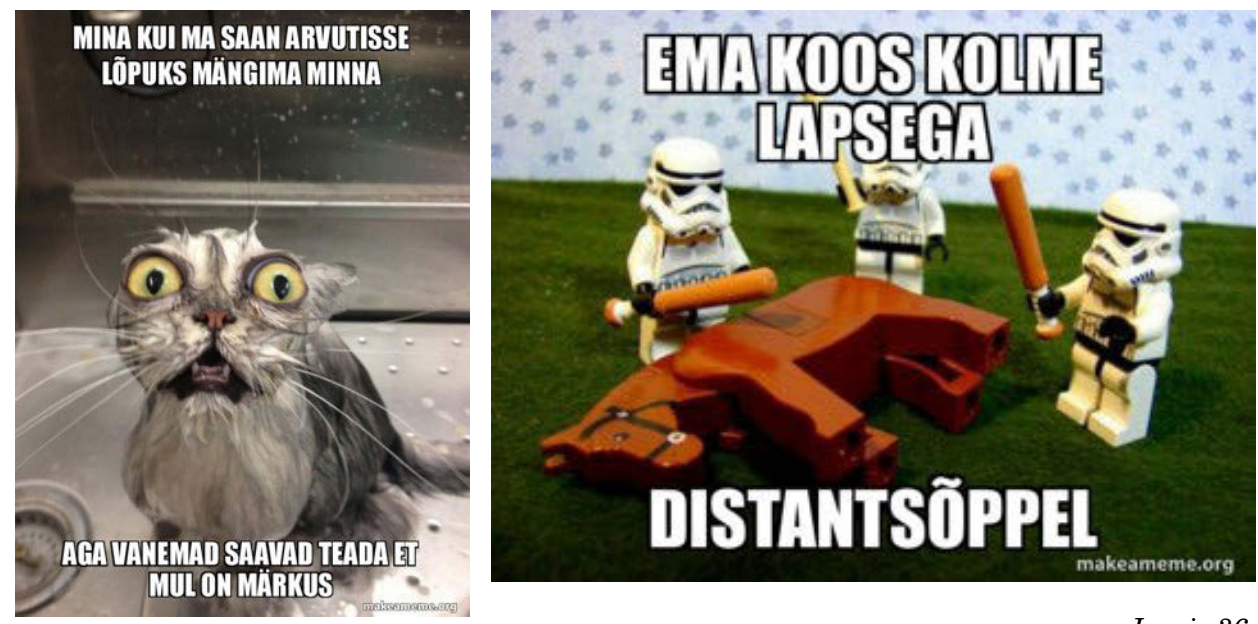

Joonis 36 .

Joonis 35 .

Lapsevanemate ühiskondlikust vastutusest pandeemiakriisis kõneleb meem (joonis 37), mis kommenteerib Kristiine gümnaasiumi sulgemist ühe õpilase koroonadiagnoosi tõttu veel enne eriolukorra väljakuulutamist (vt Vasli \& Adamson 2020). Globaalselt levinud meemimalli on integreeritud lapsevanema kaks valikut: jätta haige laps koju või saata kooli. Räppar Drake'i naeratav tundeilme koos tekstiga "Saadame haige võsukese kooli, sest ta ei tohi õppimisest puududa mitte mingil juhul ja näeb suht terve välja" vihjab iroonia kaudu lapsevanema otsusele, mille tõttu lõpuks
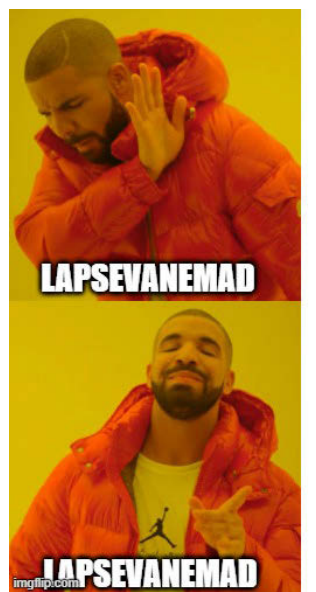

Joonis 37. https: / / www.reddit.com/r/Eesti / comments/fekgtt/mis_juhtus_kristiines_ tegelikult_parandatud/. terve kool suleti. See konkreetne üksus on väheseid kaugõppemeeme, millel on otsene seos kohaliku juhtumiga.

Lõpuks kannavad mitmed meemid ideed, et kaugõpe on kõigile keeruline, ka lapsevanematel on olukorrast kõrini ja pikale veniva distantsõppe tõttu võib juhtuda, et lapsevanemad leiutavad vaktsiini kiiremini kui teadlased. Mõneti kandub triksterimuster üle emadele-isadele, kes peavad kaugõppega samavõrra leidlikult toime tulema ja ennast vastutuse koorma all kaitsma. 


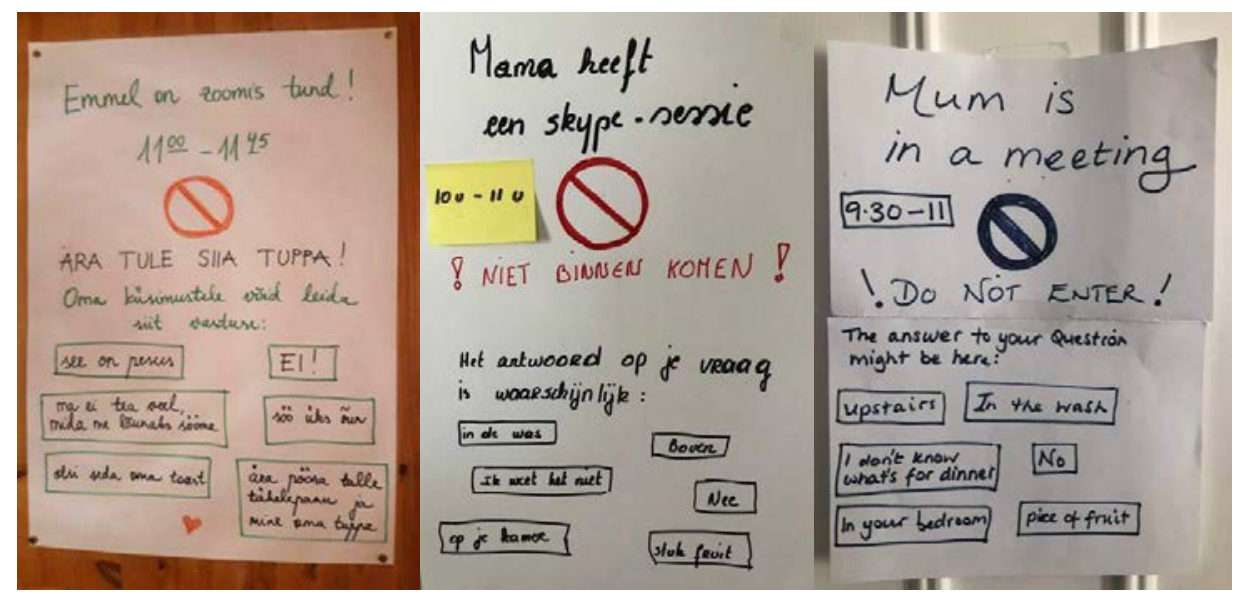

Joonis 38. ERA kogu.

Joonis 39: Belgia meem. Belg Joonis 40. ERA kogu. ium_R_1r9CuDcwFtVry10 a ntwoord.

Üks rahvusvaheliselt rohkelt jagatud meem (joonised 38-40) osutab ka rollide segunemisele: lapsevanem võib samaaegselt olla kaugõpetaja, kaugõpilase, kaugtöötaja rollis ja kuigi ta on kodus, peavad lapsed siiski ise hakkama saama.

Eri keeltes levis rohkemgi lapsevanematega seotud universaalseid naljamotiive. Kooli ja õpetajate tööga rahulolematutel lapsevanematel on lõpuks võimalus ise end õpetajana teostada ("Lapsevanem! Kui sa oled oma lapse õpetajale kunagi vihjanud, kuidas Tema oma tööd peaks tegema, siis .... NÜÜD on sinu hetk SÄRADA"). Koduõppe eripärale rõhus manitsus videotunni ajal enesekontrolli mitte kaotada ("Teavitus e-koolis. "Lugupeetud lapsevanemad. Distantsõppe ajal on lastel kaamerad ja mikrofonid sisse lülitatud ... Pidevalt on tagaplaanil alukates vanemad.") Mõlemal puhul on tegemist pedagoogidelt lapsevanematele suunatud meemiga, milles sõnumi tähenduse mõistmise seisukohalt oluline pildiosa puudub - universaalne alusmall võiks mõnikord olemata olla, tekst ise annab idee täies mahus edasi.

\section{3. Õpetaja kuvand kaugõppemeemides}

Meemidel kajastub ka õpetaja kuvand, mis on enamjaolt tõsimeelselt õppimise keskne, õpetaja esineb ülesannete andja ja kontrollija, nõudliku hindaja ja korralekutsujana. See roll langeb kokku varasemast koolifolkloorist tuntud naljadega, nn koolisõnastikuga: Õpetaja - loomataltsutaja ehk vangivalvur (RKM II 426, 605), õpetaja - tegevusvabaduse piiraja (RKM, KP 6, 459 (3), vt ka Voolaid 2004) 
Joonis 41. Segakeeles meemil on õpetajana kujutatud USA senaator Bernie Sanders, kes 2021. aasta kevadel kujunes globaalselt tuntud meemitegelaseks.

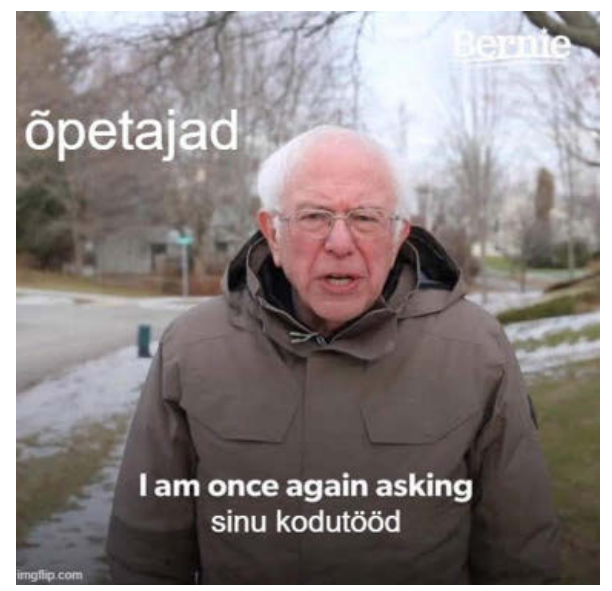

Väga hea näide on eesti- ja inglise segakeeles meem, millel on õpetajana USA senaator Bernie Sanders (joonis 41), kes ülemaailmse viraalse meemitegelase laiema kuulsuse pälvis 2021. aasta kevadel (Kalda 2021), aga nagu kinnitab see meem, oli ta meemimeistrite lemmik juba pandeemia esimese laine ajal.

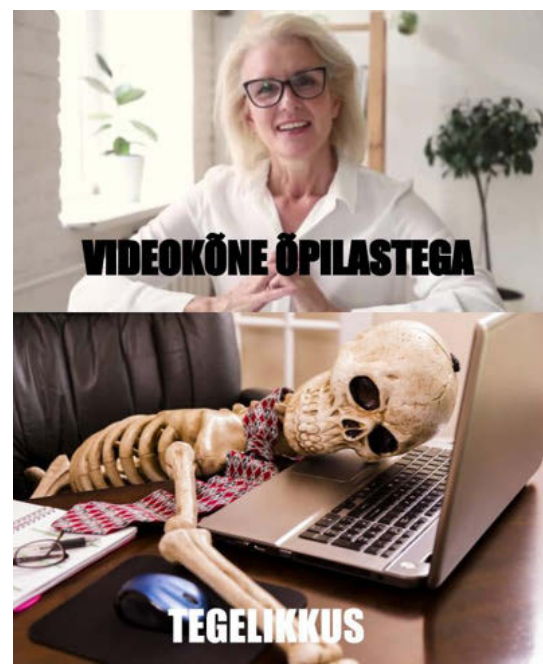

Joonis 42.

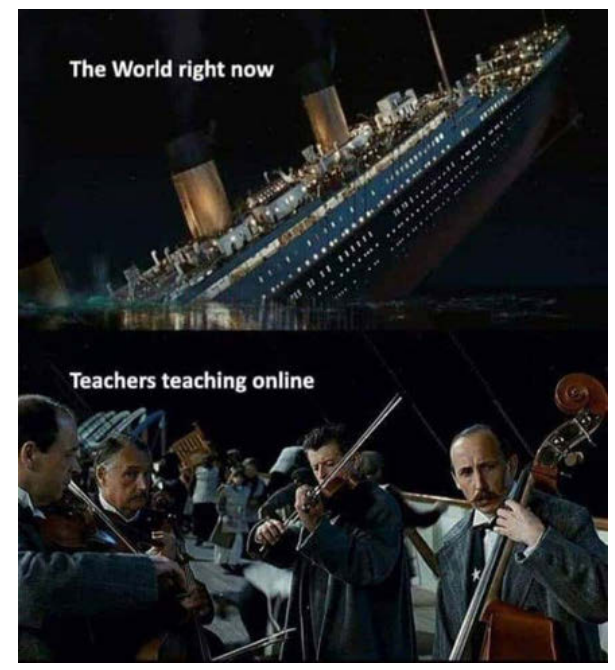

Joonis 43. Prantsuse meem. France_R_1Fn8Si VOYKumzcG 91378444_10157941934098672 9196726046865489920_n

Mitmed meemid avalikustavad ka õpetaja keerulise ülesande näida alati õpilaste silmis inspireeriv ja motiveeriv, olles ise läbipõlemise piiril (joonis 42). Prantsuse meemis (joonis 43) näeme folklooris rahvusvaheliselt väga levinud motiivi Titanicu orkestrist, kes mängis uppuval laeval, kuni vesi viiulisse tungis. 
Samasugused on veebi kaudu õpetajad - eesliinitöötajad, kes koroonakriisis kreeni vajunud maailmas töötavad kokkukukkumiseni. Vaatlusalustes meemides väljendub väga selgelt toimetulek uue olukorraga, õpilane kui trikster võib olla olukorra peremees, kes kavaldab üle õpetaja ja lapsevanemad. Samas on koroonaleviku tõkestamisest tulenenud kaugõppega kimpus ka lapsevanemad ja õpetajad, kes on laste/õpilaste elu korraldamisel väljaspool kooli ja klassi sunnitud otsima samuti triksterlikke lahendusi ja neid ka leiavad.

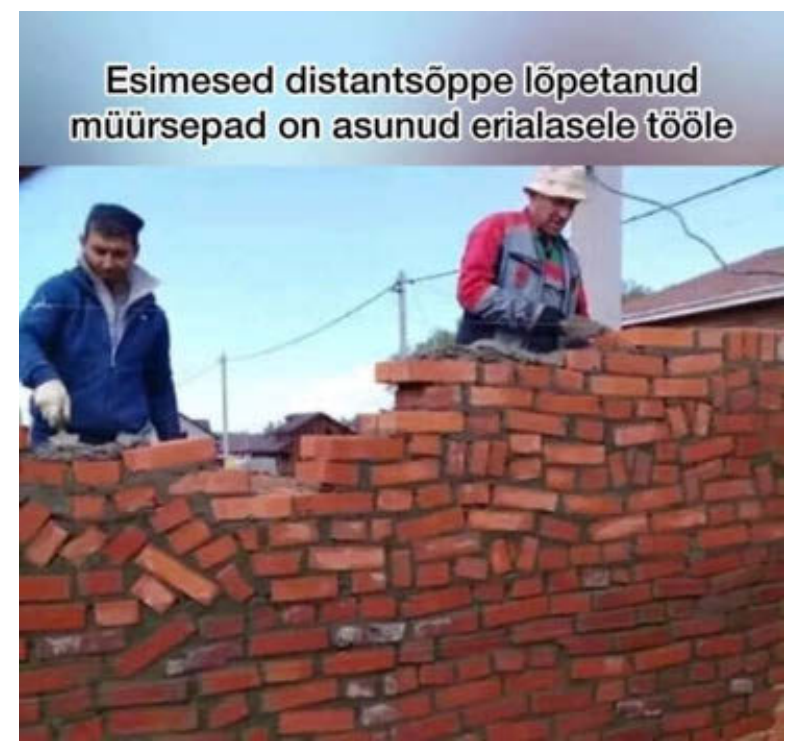

Joonis 44 .

\section{Kokkuvõtteks}

Kaugõppest inspireeritud meemimaterjal on informatiivne ajastukohane aines, mis kombineerib keerulise koroonaaja ja ühe selle aja iseloomuliku nähtuse. Puudutas ju distantsõpe väga paljusid ühiskonna liikmeid. Suuresti on eesti materjali aluseks rahvusvaheliselt tuntud globaalsed meemimallid, mis paigutatakse kohalikku keele- ja kultuuriruumi. Meemides esinevate suhtevõrgustike ja universaalsete motiivide uurimiseks sobib kvalitatiivne sisuanalüüs, mis arvestab ka koroonaaja kommunikatiivset konteksti. Koroonateema ja koroonaaeg on neis meemides harva otsesõnu esiplaanil, küll aga ilmnevad kõverpeeglis distantsõppega seotud iseärasused, mis mõnikord võivad kokku langeda kooliga seotud universaalsete stereotüüpsete teemadega (nt tahe/tahtmatus koolis käia, segadused tööaja korraldamisega). Stereotüpiseerimine toimib neis meemides 
kõigi osapoolte jaoks ühtlasi pragmaatilise tööriistana, et olukorda mentaalselt lihtsustada. Meemidele omase humoorikusega kõneldakse distantsõppest tulenevatel aktuaalsetel teemadel: vajalike tehnoloogiapädevuste puudumine, ebapiisav tehniline varustus, õppekoha ja tööaja organiseerimisega seotud keerukused, sõnumite ebaselgusest tulenevad segadused, uue korraldusega kaasnevad vaimsed või muud probleemid.

Õpilaste kui meemide põhiloojate vaatenurka analüüsides ilmneb, et kaugõppemeemid on koolihuumorina suhtlusvorm, mis pakub alternatiivse ja äärmiselt mitmekülgse vaate ühele piiranguteaja olulisele õppevormile. Materjali põhjal saab kirjeldada meeme kui keelt, milles noored mõtlevad oma (distants) õppekogemusest. Konkreetsele ainesele omane egotsentriline õpilasekeskne vaatepunkt toob esile üldisemad arusaamad, jagatud mustrid, mis põhinevad noortekultuurile omaselt vastandustel (opositsioonis on tihti mina / kaasõpilased, õpilane / õpetaja, õpilane / lapsevanem) ja liialdustel (nt õppida on liiga vähe / liiga palju).

Meemides ilmnevaid kinnistunud rollikuvandeid saab analüüsida varasemast folkloristikast tuntud ambivalentse triksteri kuju abil. Nii avanevad õpilane kui kaval olukorraga toimetulija, kes räägib meemide kaudu ka ebamugavatest teemadest, äpardustest ja probleemidest. Stereotüüpselt on õpetaja ja lapsevanema kuvand õpilase tundmustes autoritaarne kontrollija/hindaja, kuid näidatakse ka pealtnäha raudsete ja vastutavate täiskasvanute inimlikku väsimust tavaolukorrast keerukamates koroonatingimustes. Seda enam on meemid väärtuslik meedium oma hääl ja suhtumised koroonaviirusest tingitud distantsõppesse alateadlikult või teadlikult kuuldavale tuua, mistõttu on meemiloomel kriisiajal peale pelgalt meelelahutuslike eesmärkide hoopis tähtsamaid funktsioone. Kaugõppemeemid aitavad kasvuraskustega toime tulla, erinevates olukordades hakkama saada, nad on kriisiolukorras ventiil, mis võimaldab pingeid maandada. Kuid neis meemides avaldub kõverpeeglis COVID-pandeemiaga seotud hariduskriisi põhiküsimus - kas see aeg mõjutab ühe põlvkonna haridustaset pikemalt ja milline on selle aja toimejõud inimühiskonnale tulevikus. Loodame, et kriisiaegne õppekorraldus suudab laduda parema vundamendi kui ühel rahvusvaheliselt levinud meemil, mis näitab elu pärast seda, kui erialasele tööle on asunud esimesed distantsõppe lõpetanud müürsepad. Et läheks vastupidiselt 2020. aasta kevadel ringelnud koduõppevanasõnale: "Esimene klass läheb ikka aia taha."

Edaspidi on materjali võimalik uurida detailsemalt noorte keelekasutuse aspektist, valdkondadeülesest aspektist jne. 


\section{Tänusõnad}

Autori eriline tänu kuulub artikli anonüümsetele retsensentidele kõigi asjakohaste märkuste ja soovituste eest. Kirjutis on seotud Eesti Kirjandusmuuseumi uurimisprojektidega EKM 8-2/20/3 "Folkloori narratiivsed ja uskumuslikud aspektid" ja Eesti Teaduste Akadeemia ja Sloveenia Teaduste ja Kunstide Akadeemia bilateraalse uurimisprojektiga "Slovenian and Estonian Contemporary School Lore" (BI-EE/20-22-009, ARRS P6-0088). Kirjutise valmimist toetas Euroopa Liit Euroopa Regionaalarengu Fondi kaudu (Eesti-uuringute Tippkeskus, TK 145).

\section{Kommentaarid}

1 2019. aasta detsembris Hiinas Wuhani linnas alguse saanud koroonaviiruse SARSCoV-2 (COVID-19) puhang jõudis Eestisse 26. veebruaril 2020, kui ametlikult tuvastati esimene nakatunu. 12. märtsist 17. maini samal aastal kestis Eestis valitsuse kehtestatud eriolukord, mil kasutati viiruse leviku tõkestamiseks erimeetmeid: keelatud olid avalikud kogunemised, sh kultuurisündmused, konverentsid ja spordivõistlused, (õppe)töö toimus koduõppe- ja kaugtöövormis, riigipiiridel kehtis sanitaarkontroll, suletud olid kaubanduskeskused, muuseumid jms, kehtis $\mathrm{nn} 2+2$ reegel, mis tähendas, et avalikes kohtades võis liikuda kahe inimese kaupa või perekonniti ning teiste inimestega tuli hoida kahemeetrist vahemaad. (Vt ka koroonapandeemia kronoloogia Eestis https://et.wikipedia.org/wiki/Koroonapandeemia_kronoloogia_Eestis - 05.11.2021.)

2 Haridus-ja Noorteamet (Harno) on Haridus-ja Teadusministeeriumi haldusala valitsusasutus, mis tegeleb Eesti riigi haridus- ja noortepoliitika rakendamisega (https://harno.

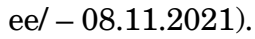

\section{Arhiiviallikad}

Eesti Kirjandusmuuseumi folkloristika osakonna teadusarhiiv EFITA (kataloogid EFITA F33, EFITA F36).

\section{Kirjandus}

Apo, Satu 1995. Naisen väki. Tutkimuksia suomalaisen kansanomaisesta kultuurista ja ajattelusta. Helsingi: Hanki ja Jää.

Attardo, Salvatore (toim) 2014. Encyclopedia on humor studies 1-2. Thousand Oaks, California: Sage Publications.

Bauer 2021 = Bauer, Tat'iana 2021. Distantsionnoe obuchenie: osnovnye motivy, obrazy i prostranstvenno-vremennye kharakteristiki (na materiale internet-memov). 
Nam, I. V. (vast toim). XIV kongress antropologov i etnologov Rossii. Sbornik materialov Tomsk 6.-9.06.21. Tomsk: Izdatel'stvo Tomskogo gosudarstvennogo universiteta, lk 668 (https://rusanthro.files.wordpress.com/2021/08/d0a1d091d09ed0a0d09dd098d09a-d09c d090d0a2d095d0a0d098d090d09bd09ed092-xiv-d09ad090d0add0a0.pdf-10.11.2021).

Brinton, Daniel 1868. The Myths of the New World: A Treatise on the Symbolism and Mythology of the Red Race of America. New York: Leypoldt and Holt.

Davis, Dineh 2008. Communication and humor. Raskin, Victor (toim). The primer of humor research. Humor Research 8. Berlin \& New York: De Gruyter, lk 543-568 (DOI: 10.1515/9783110198492.543).

Deckers, Lambert \& Buttram, Robert T. 1990. Humor as a Response to Incongruities Within or Between Schemata. Humor - International Journal of Humor Research 3 (1), lk 53-64 (DOI: 10.1515/humr.1990.3.1.53).

ENVTL 2020 = Voogla, Helen ja Purre, Merle. Noorte mured ja vajadused eriolukorras: Eesti Noorte Vaimse Tervise Liikumise küsitluse kokkuvõte (https://envtl.ee/wp-content/ uploads/2020/04/Noorte-mured-ja-vajadused-eriolukorras-Kokkuv\%C3\%B5te-ENVTLilt. pdf - 10.11.2021).

Hiiemäe, Reet 2016. Folkloor kui mentaalse enesekaitse vahend: usundilise pärimuse pragmaatikast. Dissertationes Folkloristicae Universitatis Tartuensis 25. Tartu Ülikooli Kirjastus (https://dspace.ut.ee/handle/10062/54880 - 10.11.2021).

Hiiemäe, Reet \& Kalda, Mare \& Kõiva, Mare \& Voolaid, Piret 2020. Koroonakriisi rahvapärased väljendused Eestis: Folkloori taaskasutus kui toimetulekuviis. Keel ja Kirjandus 12, lk 1011-1032 (https://keeljakirjandus.ee/wp-content/uploads/2020/12/R.HIIEM\%C3\%84E-M.-KALDA-M.-K\%C3\%95IVA-P.-VOOLAID.pdf - 10.11.2021).

Jaago, Tiiu 2018. Elulugu folkloristlikust vaatepunktist. Mäetagused 71, lk 5-24 (DOI: 10.7592/MT2018.71.jaago1).

Jürgens, Anna-Sophie \& Fiadotava, Anastasiya \& Tscharke, David \& Viaña, John (ilmumas). Spreading fun: Comic zombies, Joker viruses and COVID-19 jokes. Journal of Science \& Popular Culture 4 (1).

Kalda, Mare 2021. Liikumise vahepunktid: Bernie-meemi rändest. Kõiva, Mare \& Voolaid, Piret (koost). Liikumine. Keelest meeleni VII. Katre Kikase 40. sünnipäevale pühendatud veebikonverents keskkonnas Microsoft Teams 5. märtsil 2021. Ajakava ja ettekannete lühikokkuvõtted. Tartu: EKM Teaduskirjastus, lk 7.

Kalda, Mare \& Tuisk, Astrid 2019. Koolielu kajastamine õpilaste omaloodud meemilehtedel kolmes Tartu piirkonna koolis. Mäetagused 74, lk 151-174 (DOI: 10.7592/ MT2019.74.kalda_tuisk).

kriis.ee $=$ Hetkel kehtivad piirangud. Kriis.ee (https://www.kriis.ee/et/kehtivad-piirangudja-nende-leevendused - 10.11.2021).

Krikmann, Arvo 2002. Sissejuhatavat huumorist ja rahvanaljast: ained, mõisted, teooriad. Keel ja Kirjandus 12, lk 833-847.

Krull, Hasso 2006. Loomise mõnu ja kiri. Essee vanarahva kosmoloogiast. Loomingu Raamatukogu. Tallinn: Kultuurileht. 
Kuipers, Giselinde 2009. The sociology of humor. Raskin, Victor (toim). The Primer of Humor Research. Humor Research 8. Mouton de Gruyter (https://doi. org/10.1515/9783110198492.361).

Kuperjanov, Maris 2020. Koroonaviiruse SARS-CoV-2 algusfaasi vastukaja sotsiaalmeedias. Mäetagused 76, lk 5-28 (DOI: 10.7592/MT2020.76.kuperjanov).

Lagerspetz, Mikko 2017. Ühiskonna uurimise meetodid. Sissejuhatus ja väljajuhatus. Tallinn: TLÜ Kirjastus.

Laherand, Meri-Liis 2008. Kvalitatiivne uurimisviis. Tallinn: M.-L. Laherand.

Laineste, Liisi \& Voolaid, Piret 2016. Laughing across borders: Intertextuality of internet memes. European Journal of Humour Research 4 (4), lk 26-49 (DOI: 10.7592/ EJHR2016.4.4.laineste).

Shifman, Limor 2013. Memes in Digital Culture. The MIT Press Essential Knowledge Series. Cambridge: MIT Press.

Vasli, Karoliina \& Adamson, Sarah 2020. Tallinna Kristiine gümnaasiumis avastati õpilasel koroona, kool suletakse kaheks nädalaks. Delfi, 6. märts (https://www.delfi. ee/artikkel/89151055/tallinna-kristiine-gumnaasiumis-avastati-opilasel-koroona-koolsuletakse-kaheks-nadalaks - 10.11.2021).

Voolaid, Piret 2004. Eesti keerdküsimused. Tartu: EKM Teaduskirjastus (http://www. folklore.ee/Keerdkys - 11.11.2021).

\section{Summary}

\section{Representing distance learning in the memes of the first wave of the COVID-19 pandemic: Internet humour as a way of coping and self-defence}

\section{Piret Voolaid}

Senior Research Fellow

Executive Manager of the Centre of Excellence in Estonian Studies

Department of Folkloristics, Estonian Literary Museum

piret.voolaid@folklore.ee

Keywords: COVID-19, crisis management, distance learning, humour, memes, school lore, visual communication

Restrictions and special measures were imposed around the world to prevent the spread of the COVID-19 virus, one of the most important of which was certainly the reorganization of learning and work as a home-based activity. During the first wave of the COVID-19 pandemic, schools in Estonia remained closed from 16 March 2020 until the end of the schoolyear; further periods of countrywide distance learning were imposed also throughout the 2020/2021 schoolyear. 
The new way of life that accompanied the special situation was also reflected in widespread folklore, including internet memes. Defining memes as "(post)modern folklore" that expresses and shapes shared norms and values within communities, my article analyses the depiction of distance learning in Estonian memes, highlighting different points of view: the position of the students, the teachers, and the parents.

The source data comes from the meme collection of the research archive of the Department of Folkloristics of the Estonian Literary Museum, which consists of more than 2,000 meme units collected during the crisis period. Some data were collected separately, for example, Tartu Variku School organized a meme competition "My distance learning" for the students of Tartu schools in April 2020 (541 memes). The comparative global collection (12,000 units) comes from the international project of corona folklore and -humour research "Humour during the global corona crisis" led by Giselinde Kuipers (Leuven Catholic University) and Mark Boukes (Amsterdam University); the project involves researchers from more than 30 countries.

The study addresses the following questions: What local features emerge in distance learning memes that spread during the pandemic? How have students used other cultural resources in these memes (e.g. pop culture elements known from literature, cinema, music and other important cultural texts)? Whether and how these memes express, for example, family relationships (between children/youngsters and parents), school relationships (between students and teachers), what patterns of distance working are prevalent, etc.

The meme material which has been inspired by distance learning is a fascinating contemporary subject that combines the challenging COVID-19 pandemic and distance learning as a characteristic feature of this period. Students who are the main creators of the memes regard the humorous memes about distance learning as a form of communication which offers an alternative and multifaceted perspective on this important method of learning during lockdown.

The Estonian material is largely based on internationally known universal meme templates that have been adapted to the local language and cultural space. When investigating the social networks and universal motifs reflected in the memes, it is important to rely on the qualitative content analysis. It is worth noting that the subject of COVID-19 and the pandemic period are rarely explicitly mentioned in the memes.

The egocentric or student-centred perspective that is characteristic of this specific material highlights the general attitudes and shared patterns that are based on opposition, which is typical of youth culture. The common pairs of opposition are me/classmates, student/teacher, and student/parent.

The stereotypical roles reflected in the memes can be analysed figuratively via the ambivalent trickster figure, known from earlier folklore studies. Students are shown as cunning go-getters who use memes to discuss uncomfortable issues, mishaps, and problems. Stereotypically, the image of a teacher, but also that of a parent, is that of an authoritarian supervisor, a grade giver from the students' perspective. This makes memes a highly important channel for schoolchildren to make their voice heard, either consciously or subconsciously. In the future, the material could be investigated in even greater detail from the aspect of youth language use and emotions, the interdisciplinary aspect, etc. 
Piret Voolaid on Eesti Kirjandusmuuseumi folkloristika osakonna vanemteadur, Eesti-uuringute Tippkeskuse tegevjuht. Peamised uurimisteemad on folkloori lühivormid (mõistatuste liigiline mitmekesisus ja sotsiokultuurilised kontekstid, vanasõnade kaasaegsed kasutuskontekstid), laste- ja noortefolkloor kui ühiskondlike muutuste ja hoiakute indikaator, meediafolkloor, sh interneti sotsiaalmeedia ilmingud, multimodaalsed ja visuaalsed folkloorivormid (nt paröömiline grafiti, piltmõistatused) kui nüüdisühiskonna sünkreetlised kultuurinähtused. Ta on tegelenud ka spordifolkloristika ehk spordifolkloorile keskenduva uurimissuuna arendamisega, koostanud mitmeid folkloori lühivormide andmebaase, avaldanud teadusartikleid, toimetanud artiklikogumikke ja ajakirjade erinumbreid.

Piret Voolaid is Senior Research Fellow at the Department of Folkloristics of the Estonian Literary Museum, and an Executive Manager of the Centre of Excellence in Estonian Studies. She defended her PhD ("Estonian Riddles as a Folklore Genre in a Changing Cultural Context") in the field of Estonian and comparative folklore at the University of Tartu in 2011. Her current interests include minor forms of folklore (subgenres of Estonian riddles, proverbs in their various contemporary contexts), children's and youth folklore, Internet, and sports lore. She has compiled academic comprehensive databases of the subgenres of riddles (droodles, joking questions, compound puns, abbreviation riddles, etc.), and a database of graffiti. She has written several studies on the topic and compiled popular editions on the basis of the database materials. She has guest-edited special issues of the journals Folklore: EJF and Mäetagused, and has been editor of some monographs.

piret.voolaid@folklore.ee 